\title{
Análise geral da qualidade da vida aquática na margem oeste da Lagoa São Simão, Rio Grande do Sul
}

\author{
Analysis of the aquatic life quality on the western shore of Lagoa São Simão, Rio Grande do Sul
}

Victor Rodrigues Aragão', Victor Hugo Silva Veloso²

${ }^{1}$ Discente do curso de Engenharia Ambiental da Universidade Federal de Santa Maria - UFSM. RS - Brasil

${ }^{2}$ Mestrando em Biotecnologia e Recursos Genéticos - Uso Sustentável da Biodiversidade; Programa de Pós-graduação em Biotecnologia - Universidade Estadual de Montes Claros - UNIMONTES. Montes Claros, MG - Brasil

\section{Resumo}

Por meio de uma pesquisa de natureza documental, o presente trabalho teve por objetivo analisar de uma forma geral a qualidade da vida aquática da margem oeste da Lagoa São Simão, região litorânea do Rio Grande do Sul, durante os primeiros doze anos do século XXI, em função dos parâmetros: nitrogênio amoniacal, potencial hidrogeniônico e oxigênio dissolvido, encontrados no recurso hídrico. Seu modelo de desenvolvimento foi baseado em metodologias de caráter documental, assim como o uso de técnicas metodológicas quali-quantitativas que promoveram o alcance do objetivo proposto. A análise revelou que a lagoa apresentou índices de nitrogênio amoniacal acima do recomendado em nove anos não consecutivos durante o período em questão, e que suas causas podem ser explicadas pelas precipitações no litoral médio do Rio Grande do Sul, além de materiais e elementos orgânicos e inorgânicos oriundos de regiões diferentes das do recurso hídrico. O potencial hidrogeniônico se apresentou dentro do padrão permitido em nove dos doze anos analisados e o oxigênio dissolvido esteve dentro do padrão em todo o período. A positiva oxigenação nos doze anos pode ser explicada pela baixa profundidade da margem oeste da Lagoa São Simão, além da alta hidrodinâmica do sistema aquático e pelos fortes ventos da região litorânea, nos quais proporcionaram concluir que a mesma apresentou, no período em questão, condições ótimas para manutenção da vida aquática existente no local.

Palavras-chave: Qualidade, Vida aquática, Recurso hídrico, Hidrodinâmica.

\begin{abstract}
Through a survey of documentary nature, the present study aimed to analyze in general the quality of the aquatic life of the western shore of Lagoa São Simão, the coastal region of Rio Grande do Sul, during the first twelve years of the century, against the parameters: ammonia, hydrogen potential and dissolved oxygen found in the water resource. Its development model was based on methodologies documentary character, as well as the use of qualitative and quantitative methodological techniques that promoted reach the proposed objective. The analysis revealed that the pond had rates of ammonia nitrogen above the recommended nine years out during the period in case, and their causes can be explained by the average rainfall of the coast of Rio Grande do Sul, as well as materials and organic elements and inorganic different regions of the water resource. The hydrogen potential is presented within the standard allowed in nine of the twelve years examined, and dissolved oxygen was within the standard throughout the period. The positive oxygenation twelve years can be explained by the low depth of the western shore of Lagoa São Simão, besides the high hydrodynamics of aquatic systems and the strong winds of the coastal region, where provided to establish that it had, in the period, conditions great for maintaining aquatic life at the locus.
\end{abstract}

Keywords: Quality, Aquatic life, Water resource, Hydrodynamics. 


\section{INTRODUÇÃO}

A qualidade da água é influenciada por diversos fatores, por isso, devem ser promovidas pesquisas e análises tanto de caráter físico-químico quanto de fatores biológicos, não apenas em processos congênitos, mas também de cunho sintético (CARMOUZE, 1994).

Ainda de acordo com Carmouze (1994), os ciclos biogeoquímicos são essenciais para a compreensão dos ambientes relativos à água. Nesses, diversos elementos se encontram sob formas distintas, como é o caso do nitrogênio; que pode se apresentar nas formas de amônia, amoníaco, nitrato, nitrito e óxido nitroso. A quantidade e a procedência de seus constituintes podem instaurar a capacidade de produção completa do meio aquático; além disso, a maneira como se dispõem contraprovam o montante de matéria algal viva (SIPAÚBA-TAVARES, 1998).

A amônia ou nitrogênio amoniacal é originado por processos de desagregação e dissolução de matéria composta de carbono; é uma espécie de substância alterável e de caráter não agregativo, em que não tem a capacidade de acometer perdas fisiológicas em seres humanos ou animais; todavia, ao se apresentar em valias maiores tem a capacidade de dificultar a respiração de sistemas aquáticos, principalmente de peixes, e em outros casos, acarreta a mortandade desses por asfixia. Os elementos combinados com nitrogênio e também a níveis orgânicos martirizam desagregação a nitrato, também se apresentando na forma de amônia. Com isso, a manifestação desta determina poluição recente. Sendo "o nitrogênio amoniacal total, a soma do gás amônia $\left(\mathrm{NH}_{3}\right)$ e do íon amônia $\left(\mathrm{NH}_{4}\right)$ " (PROGRAMA ÁGUA AZUL, 2013).

$O$ excesso de soluções aquosas de amoníaco e nitrato, que são aspectos que só se podem desenvolver por justaposição, instituem um dos maiores entraves no que diz respeito ao desenvolvimento considerável de peixes (KOCHBA et al., 1994). Segundo OLÁH e SZABÓ (1986 apud PEREIRA \& MERCANTE, 2005, p. 82), de maneira quantitativa, em um sistema aquático contendo peixes, a "fonte mais importante de nitrogênio para a síntese de proteína" é a amônia convertida através do plâncton.

De acordo com Kubitza (1999), para um desenvolvimento considerável de vida aquática, mormente, de peixes, os níveis de nitrogênio amoniacal não devem ultrapassar $0,05 \mathrm{mg}$. $\mathrm{L}^{-1}$.

Já o oxigênio dissolvido (OD), segundo a CETESB (2013):

[...] é um fator limitante para manutenção da vida aquática e de processos de autodepuração em sistemas aquáticos naturais e estações de tratamento de esgotos. Durante a degradação da matéria orgânica, as bactérias fazem uso do oxigênio nos seus processos respiratórios, podendo vir a causar uma redução de sua concentração no meio. Uma das causas mais frequentes de mortandade é a queda na concentração de oxigênio nos corpos d'água. O valor mínimo de oxigênio dissolvido (OD) para a preservação da vida aquática, estabelecido pela Resolução CONAMA 357/05(2) é de 5,0 mg. $\mathrm{L}^{-1}$, mas existe uma variação na tolerância de espécie para espécie.

Outro parâmetro a ser levado em conta é o potencial hidrogeniônico $(\mathrm{pH})$, que determina se um sistema aquático é mais ácido ou alcalino, isso se deve pelo número de íons $\mathrm{H}^{+}$presentes no meio. Kubitza (1999) enfatiza que para um bom desenvolvimento desses tipos de sistema, principalmente relacionados a peixes, o $\mathrm{pH}$ deve estar entre 6,5 e 8,5, sendo a oscilação inferior a 2 unid. $\mathrm{pH}$ dia $^{-1}$.

Este trabalho tem por objetivo realizar uma análise geral da vida aquática em função dos níveis de nitrogênio amoniacal, $\mathrm{OD}$ e $\mathrm{pH}$ que se fizeram presentes nos doze primeiros anos do século XXI, na margem oeste da Lagoa São Simão, região litorânea do Rio Grande do Sul. 


\section{METODOLOGIA}

A Lagoa São Simão está localizada no litoral médio do Rio Grande do Sul, próximo ao município de Mostardas; o recurso hídrico possui coordenada de latitude $(-30,95239)$ e longitude $(-50,711107)$. Está inserida na Bacia Hidrográfica do Litoral Médio (L20), como mostra a Figura 1. O acesso à lagoa se dá pela BR-101, direção Mostardas - Tavares, a 6 km na estrada para a Praia São Simão; e sua estação de monitoramento de qualidade de água superficial é vinculada à FEPAM Fundação Estadual de Proteção Ambiental RS (FEPAM, 2013).

Ainda de acordo com a FEPAM (2013), o município de Mostardas está inserido na mesorregião metropolitana de Porto Alegre e microrregião de Osório. Possuindo municípios limítrofes: Tavares (ao sul) e Palmares do Sul (ao norte). O município possui uma localização a $31^{\circ} 06^{\prime} 25^{\prime \prime}$ de latitude sul e a $50^{\circ} 55^{\prime} 16^{\prime \prime}$ longitude oeste, estando a uma altitude de 17 metros, e possui clima subtropical úmido CFA.

\section{Litoral médio do Rio Grande do Sul}

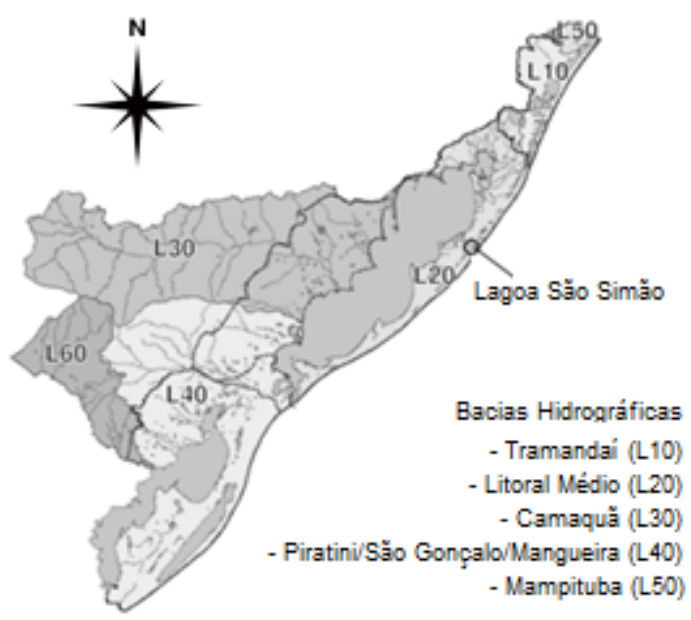

Figura 1. Área de estudo (Adaptado de FEPAM, 2006).

O monitoramento dos recursos hídricos da zona costeira vem sendo desenvolvido com os objetivos de conhecer a qualidade das águas e acompanhar suas variações espaciais e temporais, elaborar previsões sobre $\mathrm{o}$ seu comportamento, auxiliar no desenvolvimento de instrumentos de gestão e fornecer subsídios para ações saneadoras. A condição atual da qualidade da água destes corpos hídricos foi definida através da comparação dos resultados encontrados com os padrões ambientais da Resolução CONAMA 20/1986, posteriormente substituída pela Resolução CONAMA 357/2005. Foram aplicadas técnicas de análise multivariada para determinação de Índices de Qualidade da Água (IQAs), de forma a melhor caracterizar os corpos hídricos da região. As coletas são realizadas pelo Serviço de Amostragem da FEPAM, seguindo normas adotadas pela CETESB (1987). A preservação e os métodos analíticos seguem os procedimentos definidos pelo Standard Methods (FEPAM, 2013).

O presente trabalho foi originado a partir de uma pesquisa de cunho documental, que de acordo com Gil (2002, p.48), refere-se à análise de documentos e à interpretação de dados oriundos de preceitos oficiais; os mesmos encontrados neste estudo foram aprovisionados pela FEPAM - Fundação Estadual de Proteção Ambiental - RS.

Metodologias quali-quantitativas foram aplicadas para que se alcançasse o objetivo do estudo. De acordo com Santos (1999, p.46): as pesquisas de caráter qualitativo são direcionadas para a "descoberta, a identificação, a descrição aprofundada e a geração de explicações." Já a quantitativa detém como padrões a adução em função de processos estatísticos e extensão das contingências alegadas pela realidade exposta.

$\mathrm{Na}$ busca para se ratificar as problemáticas ocorridas no decorrer dos doze primeiros anos do século XXI, em relação à qualidade da vida aquática na margem oeste da Lagoa São Simão, bem como suas respectivas causas, foram coletados dados e informações dos anos de 2001 a 2012, sobre nitrogênio amoniacal, oxigênio dissolvido e potencial hidrogeniônico, encontrados na água do recurso hídrico em estudo. 


\section{RESULTADOS E DISCUSSÃO}

Através do presente trabalho, constatou-se que os anos de 2006, 2008 e 2009 foram os únicos que apresentaram suas taxas dentro do recomendado, como mostra a Figura 2, em relação a nitrogênio amoniacal, por Kubitza (1999), em que o índice não deve ultrapassar $0,05 \mathrm{mg} . \mathrm{L}^{-1}$. Já os anos que se mostraram com as maiores taxas do mesmo parâmetro foram: 2001, 2004, 2007 e 2012; apresentando excedentes de: 0,07; 0,15; 0,82 e $0,07 \quad \mathrm{mg} . \mathrm{L}^{-1}$, respectivamente. Esses extrapolamentos, que podem ser considerados em curta escala, podem ser explicados pelas precipitações que ocorrem durante o ano na região; e também pelo nitrogênio molecular coadunado no próprio recurso hídrico.

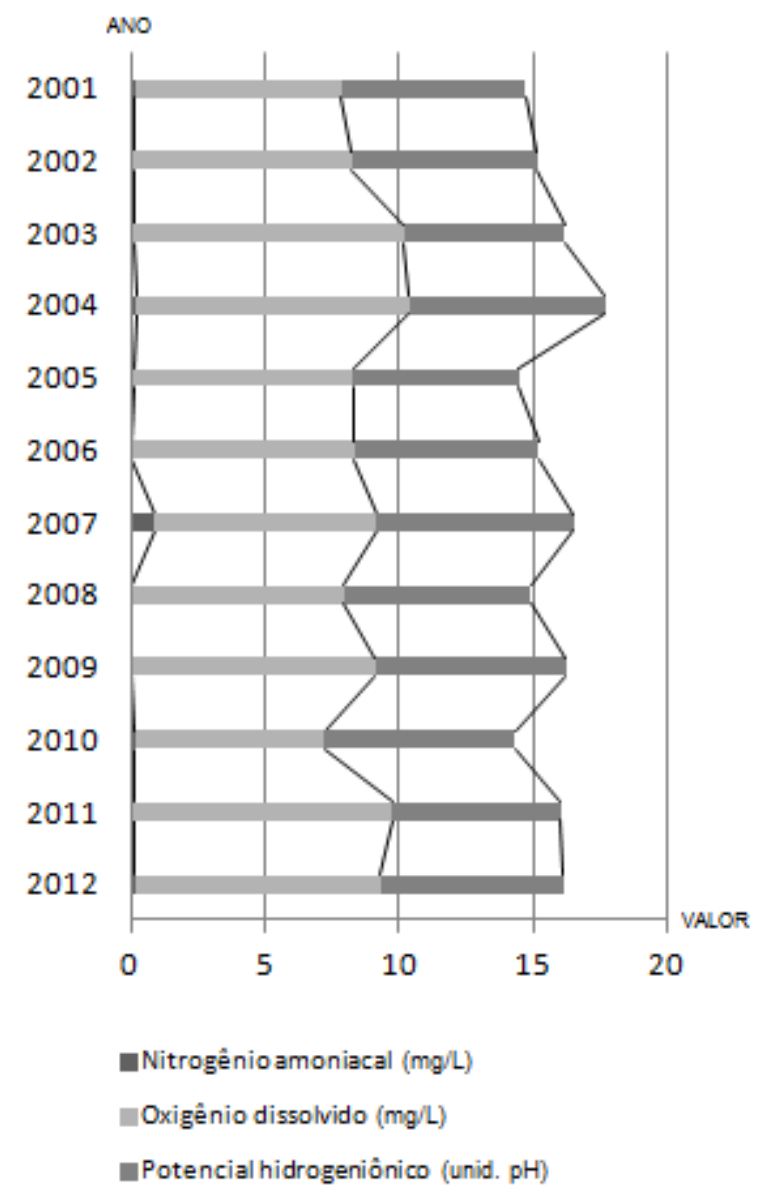

Figura 2. Números exatos relativos aos parâmetros analisados.

Fonte: FEPAM, 2013.
Quanto à oxigenação, a margem oeste da Lagoa São Simão revelou taxas melhores em relação a recursos hídricos de caráter lótico; isso pode ser explicado pela profundidade relativamente baixa da mesma, além de propriedades de movimentação, estabilidade e peso da água, somados às resistências que a própria amotina aos corpos que se movimentam em função dessa. A boa oxigenação também se deve a ventos mais resistentes do litoral médio do Rio Grande do Sul, o que promove a maciça aeração mecânica.

Ainda através da Figura 2, pode-se confirmar esses níveis de oxigenação; em que o oxigênio dissolvido permaneceu, em todos os anos em questão, dentro do padrão recomendado, estabelecido pela Resolução CONAMA $357 / 05$, que é de $5,0 \mathrm{mg} \cdot \mathrm{L}^{-1}$ ou superior, mesmo existindo alguns peixes e sistemas aquáticos que sobrevivem em condições diferentes desta; sendo possível considerar a existência de autodepuração na lagoa através desse positivo índice (FEPAM, 2000).

A Cyprinus carpio é um exemplo de espécie de peixe que tem a capacidade de admitir baixas faixas de oxigênio dissolvido, podendo até mesmo sobreviver à $3,0 \mathrm{mg} . \mathrm{L}^{-1}$, e algumas delas podem até suportar 180 dias em águas relativamente geladas e com ausência total de oxigênio dissolvido, situação denominada de anoxia. Esses índices se apresentariam de maneira nociva para as Oncorhynchus mykis, que se encontram privadas em relação a concentrações maiores de oxigênio dissolvido para suas manutenções, podendo chegar a $8,0 \mathrm{mg} \cdot \mathrm{L}^{-1}$ de OD. Já o Salminus maxillosus é capaz de se manter por quase um dia inteiro em águas de caráter anóxido, a $20^{\circ} \mathrm{C}$, ao mesmo tempo em que suas larvas não têm a mesma capacidade que os indivíduos mais "velhos". "Isto porque os valores letais dependem do estágio de vida dos organismos, sendo geralmente mais exigentes" os de caráter mais juvenis (CETESB, 2013).

De maneira geral, valores de oxigênio dissolvido menores que $2 \mathrm{mg} / \mathrm{L}$ pertencem a uma condição perigosa, denominado HIPOXIA, ou seja, baixa concentração de Oxigênio dissolvido 
na água. A concentração de oxigênio presente na água vai variar de acordo com a pressão atmosférica (altitude) e com a temperatura do meio. Águas com temperaturas mais baixas têm maior capacidade de dissolver oxigênio; já em maiores altitudes, onde é menor a pressão atmosférica, o oxigênio dissolvido apresenta menor solubilidade (CETESB, 2013).

O mesmo admitiu uma taxa de variação relativamente baixa durante os doze anos em questão, exatamente $3,09 \mathrm{mg} \cdot \mathrm{L}^{-1}$, sempre se apresentando com no mínimo 2,11 mg. $L^{-1}$ de "reserva" positiva.

Já o nitrogênio amoniacal, nos doze anos, esteve acima do recomendado em nove anos não consecutivos; esse parâmetro se encontraria também em excesso se a média total do mesmo nos doze anos equivalesse a um novo ano, alegando $0,16 \mathrm{mg} \cdot \mathrm{L}^{-1}$, com excedente de $0,11 \mathrm{mg} \cdot \mathrm{L}^{-1}$, como mostra a Figura 3.

É importante salientar que a mortandade de peixes em sistemas aquáticos naturais se deve, mormente, por problemas relacionados à redução de concentração de oxigênio, o que não foi constatado na margem oeste da Lagoa São Simão, como já comentado anteriormente (FREITAS et al., 2012).

Além disso, foi compreendido que apenas nos anos de 2003, 2005 e 2011 houve a ocorrência de $\mathrm{pH}$ levemente ácido; e em nenhum dos doze anos ocorreu $\mathrm{pH}$ excessivamente alcalino, tendo como média total de 6,83 unid. $\mathrm{pH}$, como mostra a Figura 3 (FEPAM, 2013).

Esse $\mathrm{pH}$ levemente ácido não acarretou prejuízos à Lagoa São Simão no decorrer dos doze anos em questão, porém, se esses índices passarem a ser excessivamente ácidos, juntamente com temperaturas mais elevadas, o nitrogênio poderá acarretar sérios danos ao sistema aquático, uma vez apresentando toxidade (FREITAS et al., 2002; FEPAM, 2013).

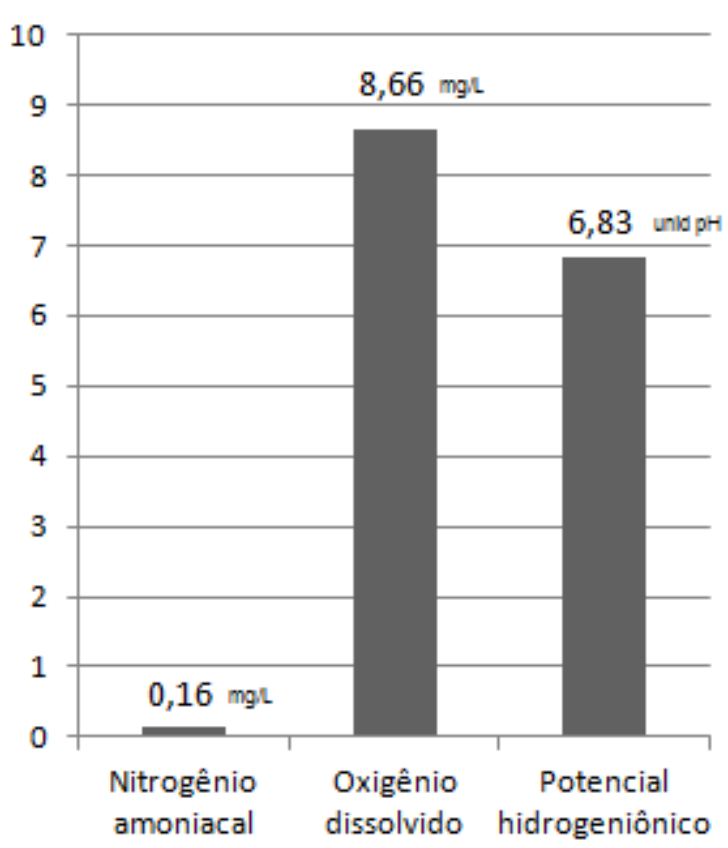

" Média de 2001 a 2012

Figura 3. Média de cada parâmetro em relação aos doze primeiros anos do século XXI.

Fonte: FEPAM, 2013.

\section{CONSIDERAÇÕES FINAIS}

Com o presente estudo foi possível concluir que o nitrogênio que extrapolou os níveis recomendados intercorre da água das chuvas do litoral médio do Rio Grande do Sul, e principalmente próximas do município de Mostardas, além de elementos constituídos por níveis altos de carbono e também de caráter inorgânico de origens que se diferem do litoral médio do estado, e também da fixação de nitrogênio molecular na própria Lagoa São Simão. Além disso, em condições de potencial hidrogeniônico e temperaturas relativamente altas, ocorre o aparecimento de nitrogênio amoniacal tóxico ao sistema aquático, o que não foi constatado na lagoa; dessa forma, peixes e vida aquática em geral, na mesma, apresentaram-se com boa qualidade nos primeiros doze anos do século XXI, e não revelou indícios de eutrofização, apresentando $\mathrm{pH}$, OD e nitrogênio amoniacal de boa qualidade. Ainda sendo possível considerar que os altos teores de oxigênio dissolvido encontrados na lagoa têm garantido 
a autodepuração do sistema aquático estudado.

\section{REFERÊNCIAS}

CARMOUZE, J.P. O metabolismo dos ecossistemas aquáticos. 1. ed. São Paulo: Edgard Blücher/Fapesp, 1994.

CETESB - Companhia Ambiental do Estado de São Paulo. Alterações físico químicas.

Disponível em:

<http://www.cetesb.sp.gov.br/mortandade/c ausas_oxigenio.php $>$. Acesso em: 19 de out. 2013.

\section{COMPANHIA DE TECNOLOGIA DE} SANEAMENTO AMBIENTAL. 1987. Guia de coleta e preservação de amostras de água. CETESB, São Paulo, SP, Brasil.

CONAMA - Conselho Nacional de Meio Ambiente, 1986. Decreto 88351 de junho de 1983. Resolução 20, de 18 de junho de 1986.

CONAMA - Conselho Nacional de Meio Ambiente, 2005. Decreto 99274, de 6 de junho de 1990. Resolução 357, de 17 de março de 2005.

FEPAM - Fundação Estadual de Proteção Ambiental - RS. Qualidade Ambiental: Região Hidrográfica das Bacias Litorâneas. Disponível em:

<http://www.fepam.rs.gov.br/qualidade/mo nitor_agua_litoral.asp $>$. Acesso em: 19 de out. 2013.

FEPAM - Fundação Estadual de Proteção Ambiental - RS. Região Hidrográfica das Bacias Litorâneas, 2006. Disponível em: <http://www.fepam.rs.gov.br/qualidade/Ima gens/litoral_geral.png>. Acesso em: 19 de out. 2013.

FEPAM, 2000. Diretrizes ambientais para o desenvolvimento dos municípios do Litoral Norte - Zoneamento Ecológico-Econômico e Proposta de Enquadramento dos Recursos Hídricos. Fundação Estadual de Proteção Ambiental - FEPAM e Programa de Gerenciamento Costeiro - GERCO. Cadernos de Planejamento e Gestão Ambiental, N. ${ }^{\circ} 1$. Porto Alegre/RS.

FREITAS, V. P. S.; BRÍGIDO, B. M.; BADOLATO, M. I. C.; ALABURDA, J.
Padrão físico-químico da água de abastecimento público da região de Campinas. Rev. Inst. Adolfo Lutz, 61 (1): 51-58, 2002. GIL, Antonio Carlos. Como elaborar projetos de pesquisa. $4^{\text {a }}$ edição. São Paulo: Atlas, 2002.

KOCHBA, M.; DIAB, S.; AVNIMELECH, $Y$. Modeling of nitrogen transformation in intensively aerated fish ponds. Aquaculture, 120: 95-104, 1994.

KUBITZA, F. 1999 Qualidade da água na produção de peixes. 3. ed. Jundiaí: Degaspari. 97p.

PEREIRA, L. P. F.; MERCANTE, C. T. J. B. A amônia nos sistemas de criação de peixes e seus efeitos sobre a qualidade da água. Uma revisão. Inst. Pesca, São Paulo, 31(1): 81 - 88, 2005.

PROGRAMA ÁGUA AZUL. Nitrogênio Amoniacal Total. Disponível em: <http://www.programaaguaazul.rn.gov.br/in dicadores_12.php>. Acesso em: 11 ago. 2013.

SANTOS, Antonio Raimundo dos. Metodologia Científica: a construção do conhecimento, Rio de Janeiro, DP\&A editora, 1999.

SIPAÚBA-TAVARES, L.H. Limnologia aplicada à aqüicultura. Boletim Técnico FUNEP, São Paulo, 1: 1-72, 1998. 